\title{
Biography of Marjorie Courtenay-Latimer - Book review
}

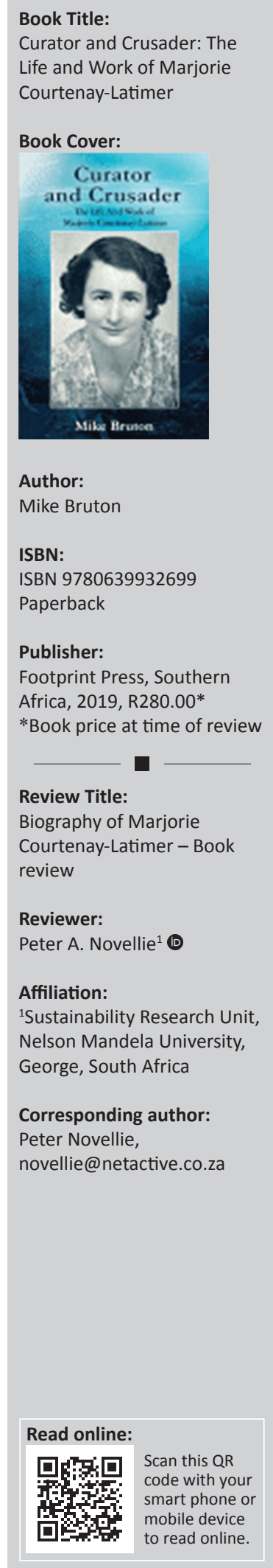

This biography tells the enchanting story of how a determined little girl, described by her father as a 'quaint little serious minded child', grew up to become Freeman Dame Dr Marjorie Eileen Dorothy Courtenay-Latimer DSc, FSAMA, MCC, DMSS - this despite her never having received a tertiary education, probably not even a matriculation certificate. Based on thorough background research from Marjorie's birth in 1907 to the end of her life in 2004, Mike Bruton builds a complete picture of how this incredible fairy tale unfolded. It is the story of how a precocious childhood passion for collecting items of natural or cultural historical interest laid the foundation for a career that made a lasting contribution to museology in South Africa and attracted an impressive variety of accolades. While still a teenager, Marge's extremely diverse field knowledge of birds, plants and cultural artefacts drew the attention, and mentorship, of a few prominent local biologists and educators and led to her appointment, at the age of only 24 years, as curator of the fledgling East London Museum, ahead of many older and better qualified applicants for the position.

Marge is best known for her role in the discovery, and presentation to the world of science, of a specimen of a living coelacanth. The extraordinary impact of this discovery is intriguingly described. Marge's persistence in ensuring that the coelacanth came to the attention of ichthyologist J.L.B. Smith, despite a series of obstacles, showed her clear appreciation of the significance of the discovery, even though she had little knowledge of fishes at the time. Her tenacity graphically illustrates Louis Pasteur's famous quote: in the fields of observation chance favours only the prepared mind. Bruton presents evidence that Marge developed a mind prepared for discovery very early in life. On 24 February 1918, Marge's 11th birthday, her father wrote, 'she is naturally gifted with a flare of finding things and knowing by instinct what is wanted or knowing where to look for what she wants' (introductory quotation to Chapter 3).

The discovery of the coelacanth in late 1938 brought world renown to both Marge and her museum. However, it would do her a great injustice to see her only in this context. As Bruton shows, Marge had already made impressive progress with the development of the East London Museum before the discovery of the coelacanth, and was to make a wide diversity of important further contributions up to and beyond her retirement at the age of 66 . Apart from her contributions to science, Marge was a natural story teller and inspirational as an educator and conservationist, which enabled her to make her museum a 'thriving hub of community activity'.

Readers with an interest in SANParks and its history will appreciate the story of the Tsitsikamma Conference (pp. 208, 212) convened by the National Parks Board (as SANParks was formerly called) at the Tsitsikamma Forest Inn in 1964. The aim of the conference was to encourage research in the Tsitsikamma Coastal National Park (TCNP), an early example of research-friendly policies that have long been followed by SANParks. Researchers were offered free accommodation, collecting permits, travel allowance and even a daily allowance of R2.00! In this aim, the conference was highly successful; Marge and several others made significant contributions. An important sequel was Marge's first scientific book on the flowering plants of the TCNP and Tsitsikamma Forest (1967), which included extensive comments on traditional medicinal uses of plants, enriched by her vast experience in the field. Another sequel was Marge's 115 page manuscript on the birds of the park and forest, written in the style of a field guide. Unfortunately - for unclear reasons (Bruton suggests that it may have been because of over-sensitivity on Marge's part to criticisms of the manuscript) - it remains unpublished in the archives of the East London Museum. Bruton raises the question of whether this work may yet be published. One feels it really should be.

Given her long life filled with achievements and awards, a biographer could easily present a haloed image of 'marvellous Marge'. However, making good use of an abundance of

How to cite this book review: Novellie, P.A., 2020, 'Biography of Marjorie Courtenay-Latimer - Book review', Koedoe 62(1), a1607. https://doi.org/10.4102/koedoe.v62i1.1607

Copyright: ( 2020. The Authors. Licensee: AOSIS. This work is licensed under the Creative Commons Attribution License. 
letters and reports written by Marge herself, and by people who knew her well, Bruton portrays a complex personality: a strong-willed, energetic and engaging people's person, enjoying the limelight but also shy and sometimes self-doubting, prone to minor deceptions that made her or her museum look good, and overly sensitive to criticism.

Bruton presents Marge's contributions in relation to a broader perspective of museums and museology in South Africa, drawing attention to the long history of museums - going back to the engagement of Andrew Smith in 1825 to establish a museum in Cape Town - and their value as sources of information collected over years by numerous dedicated scholars. The postscript to the biography describes the strong current state of the East London Museum, as well as the diverse wealth of museums in South Africa generally. This will be both reassuring and enlightening to those (including myself) who believed our natural history museums to be neglected and declining.

The story of Marge's life and work is well supported by an abundance of background material, which in no way slows down the engaging narrative. I found it gripping and difficult to put down. This book is a must-read for anyone with an interest in museology. However, because of Marge's eclectic interests and her enchanting, fairy tale career, it will be enjoyed by a wide diversity of readers. 